УДК 004.94

03.00.00 Биологические науки

ИМРВ «ПОТОК» 1.0 - ИМИТАЦИОННАЯ
МАТЕМАТИЧЕСКОЙ МОДЕЛЬ ДЛЯ
РАСЧЁТА РАСПРОСТРАНЕНИЯ И
СЕДИМЕНТАЦИИ ТЕХНОЛОГИЧЕСКИХ
НАНОСОВ В ВОДОТОКАХ ПРИ
ОПРЕДЕЛЕНИИ ВРЕДА ВОДНЫМ
БИОЛОГИЧЕСКИМ РЕСУРСАМ

Денисенко Олег Сергеевич к.б.н, SPIN-код: 3403-3102

ФГБНУ «Азовский научно исследовательский институт рыбного хозяйства», Краснодарское отделение, г. Краснодар, Россия

denisenko_o_s@azniirkh.ru

Живчиков Виталий Георгиевич

к.с.-Х.н., SPIN-код: 6132-6032

ООО «Азово-Черноморский научный центр

рыбохозяйственных исследований», г. Краснодар,

Poccuя,zvg-vint@mail.ru

В статье приведено описание и алгоритм работы имитационной математической модели ИМРВ «Поток» 1.0, предназначенной для расчёта параметров распространения и седиментации технологических наносов в водотоках.

Актуальность имитационной модели обусловлена необходимостью определения интегральных показателей (объём воды, протёкшей через области шлейфа с заданной концентрацией взвеси; средний слой наилка; удельная плотность заиления дна в расчётной зоне) при расчете вреда водным биологическим ресурсам от осуществления различных видов хозяйственной деятельности в соответствии с методикой исчисления размера вреда, причинённого водным биологическим ресурсам, утвержденной приказом Федерального агентства по рыболовству №1166 от 25.11.2011 г.

Использование имитационной математической модели ИМРВ «Поток» 1.0 позволит повысить достоверность расчетов при определении вреда водным биологическим ресурсам, а также привести деятельность расчёта параметров распространения и седиментации технологических наносов в водотоках в соответствие с действующими нормативными правовыми актами Федерального агентства по рыболовству

Ключевые слова: ИМИТАЦИОННОЕ МОДЕЛИРОВАНИЕ, ИМРВ «ПОТОК» 1.0, РАСЧЕТ ВРЕДА, ВОДНЫЕ БИОРЕСУРСЫ, ИХТИОФАУНА, ШЛЕЙФ ДОПОЛНИТЕЛЬНОЙ МУТНОСТИ, ИНТЕГРАЛЬНЫЕ ПОКАЗАТЕЛИ
UDC 004.94

Biological sciences

\section{SMDS "POTOK" 1.0 - A SIMULATION \\ MATHEMATICAL MODEL FOR CALCULATION OF DISTRIBUTION AND SEDIMENTATION OF TECHNOLOGICAL ALLUVIUMS IN WATERCOURSES FOR DETERMINATION OF HARM TO WATER BIOLOGICAL RESOURCES}

Denisenko Oleg Sergeyevich

Cand. Biol. Sci., SPIN-code: 3403-3102

FSBSI Azov Sea research fisheries Institute, Krasnodar branch, Krasnodar, Russia

denisenko_o_s@azniirkh.ru

Zhivchikov Vitaly Georgiyevich

Cand. Agr. Sci., SPIN-code: 6210-0979

JSC Azovo-Chernomorsky Scientific Center of

Fishery Researches, Krasnodar, Russia, zvg-vint@mail.ru

The article gives the description and the algorithm of the simulation model SMDS "Potok" 1.0, designed to calculate the parameters of distribution and sedimentation of technological alluviums in watercourses. The relevance of the simulation model is due to the need to determine the integral indicators (the volume of water flowing through the areas of the plume with a predetermined suspension concentration, the average layer of the silt, the specific density of the bottom silt in the calculated zone) when calculating the harm to water biological resources from the implementation of various economic activities in accordance with the methodology of calculation of damage caused to water biological resources approved by the order of the Federal Agency for Fisheries No. 1166 of 25.11.2011. Usage of the simulation model of SMDS "Potok" 1.0 will increase the reliability of calculations in determining the damage to water biological resources, as well as bring the calculations of parameters of distribution and sedimentation of technological alluviums in watercourses in accordance with the current regulatory legal acts of the Federal Agency for Fisheries

Keywords: SIMULATION MODELING, SMDS "POTOK" 1.0, CALCULATION OF HARM, WATER BIOLOGICAL RESOURCES, ICHTHYOFAUNA, PLUME OF ADDITIONAL TURBIDITY, INTEGRAL INDICATORS 
Doi: 10.21515/1990-4665-129-046

\section{Введение}

Производство различных видов работ на водных объектах рыбохозяйственного значения в подавляющем большинстве случаев оказывает негативное влияние на водные биоресурсы и среду их обитания. При этом, в соответствии с действующим законодательством Российской Федерации в области рыболовства и сохранения водных биологических ресурсов, должны предусматриваться и осуществляться мероприятия по максимальному предотвращению негативных последствий такого воздействия. В случае если указанные мероприятия не позволяют избежать негативного влияния на экологические условия водных объектов и полностью обеспечить сохранение и воспроизводство их биоресурсов, производится оценка причиняемого биоресурсам вреда и разработка компенсационных мероприятий.

Большинство проводимых работ, затрагивающих акваторию водных объектов рыбохозяйственного значения, сопровождаются формированием шлейфов дополнительной мутности, наносящих значительный ущерб биоценозам. Высокое содержание взвесей в воде вызывает гибель организмов фитопланктона, зоопланктона и зообентоса, являющихся неотъемлемым компонентом питания рыб. В итоге происходит значительное снижение продукционных характеристик водных объектов рыбохозяйственного значения.

В соответствии с Методикой исчисления размера вреда, причиненного водным биологическим ресурсам, утвержденной Федеральным агентством по рыболовству приказом № 1166 от 25.11.2011 г. [12], сведения о количественной оценке интенсивности факторов воздействия, объёмов, площадей и зон их влияния выполняются посредством имитационного (математического) моделирования с 
использованием специальных компьютерных программ.

Учитывая вышеизложенное, была разработана имитационная математическая модель ИМРВ «Поток» 1.0, предназначенная для расчёта параметров распространения и седиментации технологических наносов в водотоках. Федеральной службой по интеллектуальной собственности (РОСПАТЕНТ) имитационная математическая модель ИМРВ «Поток» 1.0 внесена в реестр программ для ЭВМ (свидетельство о государственной регистрации программы для ЭВМ № 2017613750, правообладатель ООО «Азово-Черноморский научный центр рыбохозяйственных исследований»). Сертификатом соответствия POCCRU.04ЖИГ0.00081 (изготовитель ООО «Азово-Черноморский научный центр рыбохозяйственных исследований», срок действия сертификата - по 21.06.2019 г.) подтверждено соответствие требованиям следующих нормативных документов: ГОСТ 19179-73, ГОСТ 17.1.1.02-77, ГОСТ 826793, ГОСТ 12536-2014, ГОСТ Р ИСО/МЭК 9126-93, ГОСТ 17.1.3.07-82, ГОСТ Р ИСО/МЭК 12119-2000, ГОСТ 27065-86, ГОСТ Р ИСО/МЭК 159102002, ГОСТ 17.1.3.13-86.

\section{Материал и методы}

В качестве методической основы при разработке имитационной математической модели ИМРВ «Поток» 1.0 положены нормативные документы и литературные данные [1-15].

В модели ИМРВ «Поток» 1.0 указанные методики являются взаимодополняющими друг друга, при этом моделирование производится с расчётом всего необходимого набора площадей $P_{i}$ и поперечных размеров облака дополнительной взвеси $B_{2 i}$.

Расчёт ведётся для величины превышения мутности над фоновыми значениями в предположении, что фоновая мутность соответствует гидравлическим характеристикам водотока и не приводит к заилению русла. При этом дополнительная (технологическая) мутность 
рассматривается как загрязняющее вещество.
Модельный
расчёт
распространения
И
седиментации
технологических наносов в водотоке посредством ИМРВ «Поток» 1.0, ведётся последовательно по этапам (рис. 1).

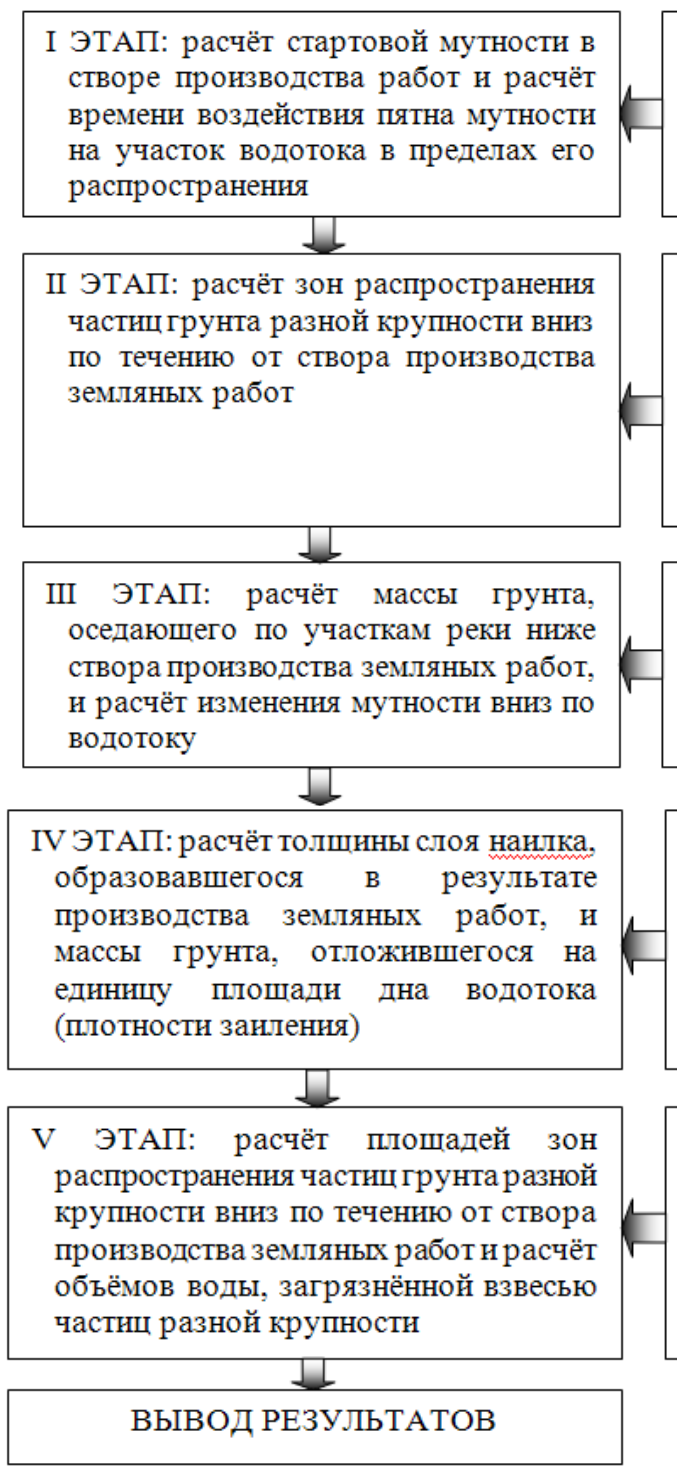
ИСХОДНЫЕ ДАННЫЕ: объём перемешаемого (извлекаемого) грунта; пронзводительность землеройной техникн; характернстика механнческого состава грунта; процент уноса грунта; морфометрические характеристикн реки (ширина и глубнна); скорость течения

ИСХОДНЫЕ ДАННЫЕ: гранулометрическнй состав грунта (по фракциям, в \% массы); стандартная гидравлическая крупность частиц расчётного диаметра; температура воды; температурный поправочный коэффнциент к значенню гидравлической крупности; морфометрнческие характеристикн рекн (ширнна и глубнна); скорость течения

ИСХОДНЫЕ ДАННЫЕ: результаты расчёта I и II этапов

ИСХОДНЫЕ ДАННЫЕ: результаты расчёта II этапа
ИСХОДНЫЕ ДАННЫЕ: результаты расчёта III этапа; объём перемешаемого (извлекаемого) грунта; пронзводительность землеройной техникн; процент уноса грунта; морфометрические характеристики реки (ширнна и глубнна); скорость течения

\section{Рисунок 1 - Схема последовательности обработки данных с помощью модели ИМРВ «Поток» 1.0}

\section{Результаты и обсуждение}

Все естественные водотоки несут в своей толще и передвигают по дну твёрдые частицы грунта (или наносы). 
Наносы включают в себя взвешенные наносы (наносы, переносимые водным потоком во взвешенном состоянии) и влекомые наносы (наносы, перемещаемые водным потоком в придонном слое и движущиеся путем скольжения, перекатывания или сальтации) [3].

Причиной взвешивания и переноса наносов во взвешенном состоянии является наличие в потоке вертикальных составляющих мгновенных или пульсационных скоростей, величина которых превосходит гидравлическую крупность «U» взвешиваемых наносов или, иными словами: превышает скорость выпадения частиц этих наносов в спокойной воде.

Передвижение наносов во влекомом состоянии (донных наносов) связано с наличием значительных придонных скоростей потока и вихревых образований воды, отделяющихся от дна.

Согласно теории потока, если в прямолинейном открытом русле, сложенном из однородных частиц, повышать величину расхода $Q$, то при определённой скорости частицы начнут выноситься потоком. Далее при постоянном расходе воды будет происходить седиментация частиц, и дно русла потока станет стабильным, сложенным при этом из частиц, находящихся в предельном состоянии равновесия, а течение потока станет спокойным, и в нём не будут содержаться наносы.

Если при тех же условиях в створ I-I (рис. 2) будет подан определенный дополнительный расход минеральных частиц (технологических наносов, формирующихся например, в результате отсыпки дамбы), представленный фракциями, слагающими русло потока, то эти наносы, отложившись в створе I-I в виде гряды, начнут перемещаться к створу II-II.

По истечении некоторого времени, расходы наносов в створах I-I и II-II станут одинаковыми и отметка дна русла в исследуемой зоне «а» станет стабильной. 
Перенос потоком взвешенных наносов происходит вследствие турбулентного перемешивания, т. е. непрерывного обмена местами отдельных водных масс в потоке. При этом в случае незначительного насыщения потока взвешенными наносами и их малой крупности основные характеристики потока не изменяются [11].

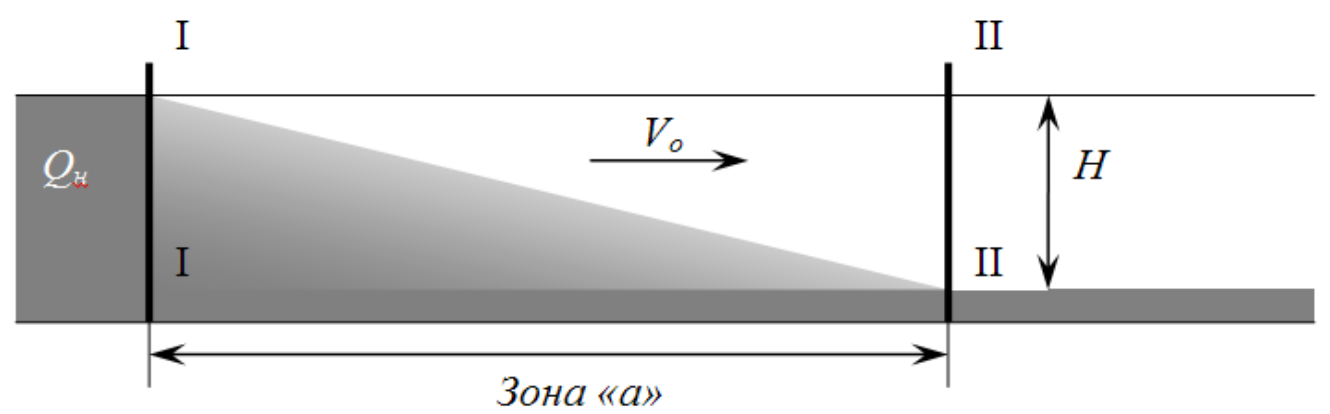

Средняя скорость $V_{o}, \mathrm{M} / \mathrm{c}$

Глубина потока $H$, м

Расход наносов (твёрдый расход, проходящий через живое сечение реки) $Q_{\text {H }}$ м $3 / \mathrm{c}$

Рисунок 2 - Схема распределения частиц наносов в русле водотока

Содержание (концентрация) взвешенных веществ - наносов в единице объёма смеси воды с наносами, выражаемое в весовых единицах мг/л, г/м³ , называется мутностью воды $[3,6]$.

Взвешенные наносы распределяются в толще потока весьма неравномерно. Наиболее крупные (с большей гидравлической крупностью) движутся в нижних слоях, где мутность достигает значительной величины, наиболее мелкие распределяются по всей глубине, однако количество их уменьшается от дна к поверхности.

Большую часть расхода наносов $Q_{\text {н }}$ - около 90\% составляют взвешенные наносы и только $10 \%$ составляют донные наносы, наиболее крупные, образующие гряды [15].

Таким образом, вымытые водотоком частицы грунта будут не только осаждаться под действием силы тяжести, но и одновременно смешиваться с водой водотока, а поэтому на некотором расстоянии от места сброса 
концентрация взвешенных частиц (мутность), будет снижаться.

В процессе производства работ, связанных с разработкой и удалением, перемешиванием или отсыпкой грунта под водой, неизбежен вынос некоторого количества частиц грунта течением из зоны работ и, как следствие, формирование дополнительных (технологических) наносов. При этом на окружающую среду отрицательное влияние оказывают следующие факторы: а) опасность уничтожения условий естественной среды механическим перемещением грунта; б) усиление воздействия токсически опасных веществ, находящихся в перемещаемых грунтах; в) вторичное загрязнение воды продуктами распада органических и химических веществ, присутствующими в донных отложениях; г) гибель животных и растительных организмов, населяющих дно водотока в месте производства работ, а также в зоне перемещения грунта или выпадения взвешенных частиц, транспортируемых потоком; д) препятствие миграции взрослых особей и молоди рыб.

Допустимое содержание взвешенных частиц в водных объектах для разных типов водопользования представлено в таблице $1[1,2]$.

Таблица 1 - Требования к содержанию взвешенных веществ в воде водотоков и водоёмов различного назначения

\begin{tabular}{|c|c|c|c|}
\hline \multicolumn{4}{|c|}{ КАТЕГОРИЯ ВОДОПОЛЬЗОВАНИЯ } \\
\hline $\begin{array}{c}\text { Хозяйственно- } \\
\text { питьевое } \\
\text { водоснабжение } \\
\text { пищевых } \\
\text { предприятий }\end{array}$ & $\begin{array}{c}\text { Для } \\
\text { купания, } \\
\text { спорта и } \\
\text { отдыха }\end{array}$ & $\begin{array}{c}\text { Водные объекты, используемые } \\
\text { для сохранения и } \\
\text { воспроизводства ценных видов } \\
\text { рыб, обладающих высокой } \\
\text { чувствительностью к кислороду }\end{array}$ & $\begin{array}{c}\text { Водные объекты, } \\
\text { используемые для } \\
\text { всех других } \\
\text { рыбохозяйственных } \\
\text { целей }\end{array}$ \\
\hline \multicolumn{4}{|c|}{ Содержание взвешенных веществ (мг/л) не должно увеличиваться больше чем на: } \\
\hline 0,25 & 0,75 & 0,25 & 0,75 \\
\hline
\end{tabular}

Оценку воздействия проведения работ в водотоке на концентрацию технологических наносов (и мутность) следует выполнять с учётом типа водного объекта и технологии работ $[11,13,15]$. Тип водного объекта 
определяет ведущие факторы распространения и трансформации поля мутности от источника загрязнения, а технология работ определяет время воздействия и интенсивность источника загрязнения. В связи с этим в составе исходных данных для моделирования распространения и седиментации технологических наносов в водотоках, в ходе намечаемой хозяйственной деятельности, используются следующие сведения:

- гидрометеорологические данные, включая расчётные расход и уровень воды, морфометрические характеристики русла, скорость течения и фоновые значения мутности;

- геологическая информация (осреднённый гранулометрический состав разрабатываемых грунтов и донных отложений);

- данные о технологическом оборудовании (в т. ч. мощности источников поступления технологических наносов), коэффициенты взмучивания и потерь (просора) грунта, перехода его во взвесь.

Такие исходные данные полностью согласуются с требованиями с п. 34 гл. III «Методики исчисления размера вреда, причинённого водным биологическим ресурсам» [12].

\section{Общетеоретические основы применяемой математической} модели

При модельных расчётах полагаем, что поступление взвеси происходит с постоянной интенсивностью и через какое-то время процесс становится установившимся. В дальней зоне концентрация взвеси уменьшается за счёт процесса турбулентного перемешивания и в результате осаждения более тяжёлых твёрдых фракций. При этом взвешенные вещества рассматриваются, как не влияющая на фоновое поле скорости жидкости примесь, перенос которой определяется лишь заданной величиной скорости течения и интенсивностью турбулентной диффузии в водотоке. В дальней зоне применим принцип суперпозиции, то есть распространение взвеси можно представить в виде движения совокупности 
отдельных невзаимодействующих облаков взвеси, образованных частицами разных размеров (диаметров). Эти облака движутся сквозь водную толщу под воздействием местных течений и осаждаются на дно. В процессе движения облака взвеси увеличиваются в размере за счёт горизонтальной турбулентной диффузии, а концентрация взвешенных веществ в них падает. Концентрацию взвеси в произвольной точке акватории при этом определяем в виде суммы концентраций пассивной примеси в отдельных облаках, включающих данную точку в рассматриваемый момент времени.

Далее для расчётов используется двумерная (усреднённая по глубине) модель, полученная из трёхмерного уравнения конвекциидиффузии плотности взвеси $\varphi$.

В основе модели лежит выражение единичного адекватного и турбулентного переноса вещества через контрольную поверхность в водной среде $r_{s}\left[\Gamma /\left(\mathrm{M}^{2} \cdot \mathrm{c}\right)\right]$ :

$$
r_{s}=v_{n} s-D \partial s / \partial n
$$

где: $v_{n}$ - компонента осредненной скорости течения, направленная по нормали $n$ к контрольной поверхности;

$s$ - концентрация вещества в точке пересечения нормали с контрольной поверхностью;

$D$ - коэффициент турбулентной диффузии в той точке.

При имитационном моделировании предусматривается деление водотока на расчётные элементы (объёмы) и запись для каждого из них уравнения неразрывности, уравнения баланса вещества и численное решение этих уравнений для всей совокупности элементов в пределах рассматриваемого случая антропогенного формирования шлейфа дополнительной мутности (разработка траншей или отсыпка дамб).

В пределах каждого элемента концентрация взвеси $s$ неизменна в пространстве и может меняться только лишь во времени [13]. 
Коэффициент турбулентной диффузии принимается постоянным для всей расчётной области. Скоростное поле в расчётной области водотока принимается неизменным во времени для всего расчётного периода. Для каждой грани расчётного элемента приписывается определённое среднее значение нормальной к ней составляющей скорости течения, то есть принимается, что на каждой грани наблюдается течение одного направления и одной интенсивности. При оценке объёма элемента используется лишь среднее значение глубины в пределах всего элемента, получаемое как среднее из средних глубин на четырёх гранях, ограничивающих элемент. Вычисление площади грани осуществляется путём умножения её ширины на среднюю глубину грани.

Моделируется нестационарное поле концентрации, при этом рассматривается общий случай переноса консервативного взвешенного в воде загрязняющего вещества. Модель позволяет выполнить расчёт распределения концентрации на заданный момент времени при заданных параметрах формирования поля (шлейфа) дополнительной мутности в заданном стационарном поле скоростей водотока.

Каждую клетку расчётной сетки обозначим индексами $i$ и $j$, показывающими её положение соответственно по координатным направлениям $x$ и $z$ (рис. 3). На этом же рисунке показаны обозначения граней расчётных элементов $a$ и $b$ - тыльная и фронтальная грани, считая по оси $x$; $c$ и $d$ - соответственно тыльная и фронтальная по направлению оси $z$.

В случае стационарного режима течений уравнение неразрывности течений контрольного элемента $i j$ будет иметь вид:

$$
q_{i j a}-q_{i j b}+q_{i j c}-q_{i j d}=0
$$

где: $q_{i j a}-$ расход воды через грань $a$ для контрольного элемента $i j$;

$q_{i j b}$ - расход воды через грань $b$ для контрольного элемента $i j$;

$q_{i j c}-$ расход воды через грань $c$ для контрольного элемента $i j$; 
$q_{i j d}-$ расход воды через грань $d$ для контрольного элемента $i j$.

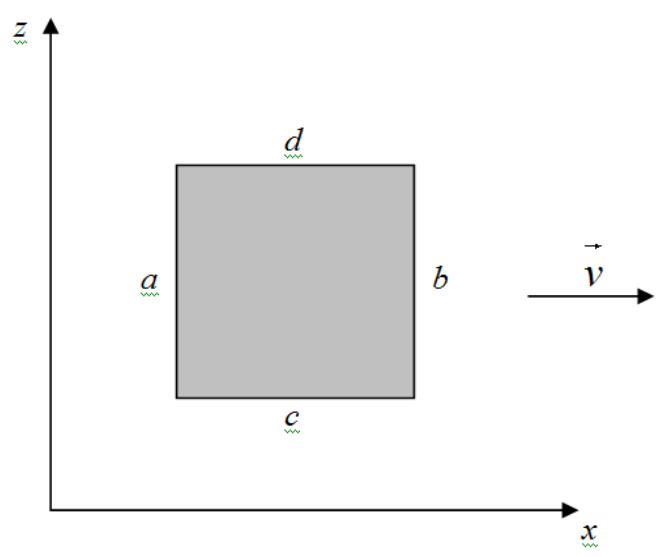

Рисунок 3 - Схема расположения расчетного элемента в двухмерной модели

Расход воды приобретает тот же алгебраический знак, что и компонента скорости, так как расход напрямую зависит от скорости. Например, для грани а, в частности, эта зависимость будет иметь вид

$$
q_{a}=v_{a} \cdot \Delta z \cdot H_{a},
$$

где: $q_{a}-$ расход воды через грань $a$;

$\Delta z$ - перемещение элемента относительно оси $z ;$

$v_{a}-$ средняя скорость в пределах грани $a$;

$H_{a}-$ средняя глубина в пределах грани $a$.

Положительные значения расходов для граней $a$ и $c$, в формуле (2), означают приток в контрольный элемент, а отрицательные для граней $b$ и $d$ - отток.

Соответственно этому условию должно удовлетворять с определенной степенью точности поле скоростей, используемое для расчета концентрации.

В рассматриваемой модели учитывается процесс снижения концентрации взвешенного вещества, для чего используется соотношение, отвечающее дифференциальному уравнению реакции первого порядка: 


$$
\partial s=k \cdot s d t
$$

где: $s$ - концентрация взвешенного вещества;

$t$ - время;

$k-$ коэффициент уравнения.

Для дальнейшего упрощения математических выкладок введём функцию $\varphi$, полученную на основании уравнения (4):

$$
\varphi_{i j}^{k}=k \cdot s_{i j}^{k} \cdot \Delta t
$$

где: $s_{i j}^{k}$ концентрация взвешенного вещества в пределах контрольного элемента $i j$ в интервал времени с порядковым номером $k$;

$\Delta t-$ интервал времени.

Результирующий вертикальный секундный перенос $q_{s n}$ твёрдых частиц, относящихся к фракции $n$ (по значению гидравлической крупности $u_{n}$ ) через единицу граничной поверхности дна и водных масс может быть выражен, согласно Методике (1987), следующей формулой:

$$
q_{s n}=\left(u_{n}+E_{n}\right) \cdot s_{n}-E_{n} \cdot s_{63 n . n},
$$

где: $s_{n}-$ средняя по вертикали частная мутность (отвечающая концентрации частиц крупностью $u_{n}$;

$s_{\text {взм.n }}$ - частная мутность взмыва для той же фракции, определяемая по формуле (7):

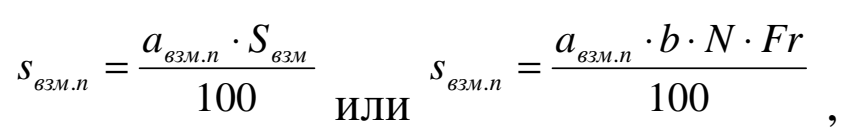

где: $S_{\text {взм }}$ - общая мутность взмыва;

$a_{\text {взм.n }}$ - процентное содержание $n$-й фракции в составе взвешенных частиц;

$b$ - коэффициент уравнения;

$N$ - безразмерное характеристическое число, зависимое от коэффициента Шези $(C)$ и её производной $(M)$;

$F r$ - число Фруда. 
Параметр $E_{n}$ вычисляется по формуле (8):

$$
E_{n}=\frac{u_{n} \cdot \Gamma}{1-\Gamma},
$$

где: $\Gamma$ - гидромеханический параметр (находится по справочной таблице), зависящий от коэффициента Шези $(C)$ и безразмерной величины:

$$
G=\frac{u_{n}}{v},
$$

где: $v$ - средняя скорость.

Расчёты ведутся по средней гидравлической крупности частиц $\left(u_{n}\right)$.

Формула (6) может быть разделена на две части, одна из которых определяет взмыв частиц (индекс «в»), а другая - их осаждение на дно (индекс «0»). При этом согласно Методике (1987), из формулы (6) непосредственно получаем следующие функции модели:

$$
\begin{gathered}
\varphi_{i j \delta}^{k}=\frac{E_{i j} s_{i j s}^{k} \Delta t}{H_{i j}}, \\
\varphi_{i j o}^{k}=\frac{\left(u_{n}+E_{n}\right)_{i j} s_{i j o}^{k} \Delta t}{H_{i j}} .
\end{gathered}
$$

Общее расчётное уравнение модели расчета изменения концентрации взвешенных частиц $\left(s_{i j}^{k+1}\right)$ приобретает вид:

$$
s_{i j}^{k+1}=s_{i j}^{k}+\varphi_{i j a}^{k}-\varphi_{i j b}^{k}+\varphi_{i j c}^{k}-\varphi_{i j d}^{k}+\varphi_{i j m}^{k}+\varphi_{i j k}^{k}-\varphi_{i j o}^{k}
$$

где: $s_{i j}^{k}$ - концентрация взвешенного вещества в расчётном элементе $i j$ в интервал времени порядковым номером $k$;

$\varphi_{i j a}^{k}, \varphi_{i j b}^{k}, \varphi_{i j c}^{k}$, и $\varphi_{i j d}^{k}-$ дифференциальные функции концентраций взвешенных частиц на соответствующих гранях $a, b, c$ и $d$ расчётного элемента $i j$ в интервал времени порядковым номером $k$;

$\varphi_{i j m}^{k}$ - дифференциальная функция концентрации взвешенных частиц дополнительно поступающих в расчётный элемент $i j$ в интервал 
времени порядковым номером $k$.

Эта модель применяется для получения генеральной схемы распространения взвешенных частиц в водотоке.

Модельный расчёт концентрации взвеси в пределах шлейфа дополнительной мутности

Схема распространения взвешенных частиц представляется следующим образом: частицы грунта различного размера (диаметра), взмученные в створе производства работ, подхватываются и уносятся течением воды, постепенно перемещаясь вниз под действием силы тяжести, при этом происходит частичное осаждение (седиментация) сначала более крупных частиц грунта, затем более мелких.

Облако частиц при распространении вниз по течению водотока расширяется в плане за счёт турбулентной диффузии. При этом плотность взвеси дополнительно уменьшается за счёт того, что взвешенные частицы занимают большую часть площади створа.

В основе моделирования осаждения загрязняющих взвешенных частиц в водотоке положено уравнение распределения их концентрации по длине струи:

$$
S_{X i}=S_{T i}+\left(S_{H i}-S_{T i}\right) \cdot e^{\left[-B_{\text {Д }} \cdot\left(u_{i}+E_{i}\right) \cdot X / Q_{\not}\right]},
$$

где: $S_{T i}$ - концентрация частиц расчётной крупности, соответствующая транспортирующей способности потока на рассматриваемом участке водотока;

$S_{H i}-$ концентрация взвешенных загрязняющих частиц, относящихся к $i$-ой фракции, в начальном поперечнике загрязнённой струи при $X=0$;

$B_{д}-$ действующий фронт работ;

$u_{i}$ - средняя гидравлическая крупность взвешенных загрязняющих частиц (расчётная крупность);

$E_{i}$ - коэффициент, определяемый в зависимости от гидравлической 
крупности частиц и гидромеханического параметра $\left(\Gamma_{i}\right)$ для $i$-ой фракции;

$X$ - длина участка, в конце которой вычисляется $S_{X i}$;

$Q_{д}-$ действующий расход воды в пределах фронта работ.

Это уравнение позволяет рассчитать изменение концентрации в потоке по направлению течения, а также выяснить направленность процесса - осаждение загрязняющих частиц или взмыв с поверхности дна частиц, осевших там ранее, и количественно определить значение аккумуляции или размыва.

Определив по формуле (14) максимальный диаметр частиц грунта, которые будут уноситься потоком, получим размер фракций грунта, по которым в дальнейшем будем проводить дальнейшие расчёты:

$$
d_{m}=\left(\frac{v}{3,6}\right) \cdot \frac{1000}{H},
$$

где: $v$ - средняя скорость водотока;

$h$ - средняя глубина водотока.

Для выделенных фракций вычисляется средняя гидравлическая крупность $u$.

Далее расчёт переноса наносов выполняется по формуле (15), позволяющей получить распределение концентрации наносов вдоль оси и вместе с тем охарактеризовать процессы взмыва и осаждения:

$$
S_{K}=S_{T}+\left(S_{H}-S_{T}\right) \cdot e^{\left[-B_{Z} \cdot(u+E) \cdot \Delta X / Q_{Z}\right]},
$$

где: $S_{K}$ - общая мутность (суммарная концентрация всех взвешенных в воде фракций) в конце расчётного участка длиной $\Delta X$;

$S_{T}$ - мутность, соответствующая транспортирующей способности потока на рассматриваемом участке водотока;

$S_{H}$ - мутность в начальном створе расчетного участка (в створе для которого определены $Q_{д}$ и $\left.B_{д}\right)$; 
$B_{д}-$ действующий фронт работ;

$u$ - средняя гидравлическая крупность взвешенных загрязняющих частиц (расчётная крупность);

$E$ - коэффициент, определяемый в зависимости от гидравлической крупности частиц и гидромеханического параметра $(\Gamma)$;

$X$ - длина участка, в конце которой вычисляется $S_{K}$;

$Q_{д}-$ действующий расход воды в пределах фронта работ.

Учитывая тот факт, что для случаев ведения производственных работ в водотоках формируется шлейф дополнительной мутности, то уравнение (15) трансформируется в следующую зависимость:

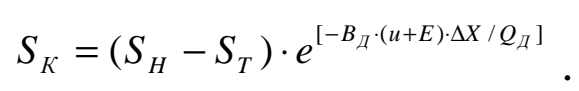

Расчёт распределения концентрации мутности по оси $X$ ведётся по формуле (16) от участка к участку. В пределах каждого участка гидравлические и морфометрические характеристики принимаются однородными. Полученное по расчёту значение мутности в конце первого расчётного участка является начальным для второго и т. д. Расчёт выполняется до получения значений мутности, обусловленных поставленной задачей (достижения допустимых значений).

Особенности расчёта концентраций взвесей при работах по разработке подводных каналов

Модель «Поток» 1.0 позволяет учитывать вид производимых в водотоке работ, при этом рассматриваются два основных вида земляных работ:

1) разработка подводных каналов;

2) отсыпка дамб.

Для каждого из них предлагается свой способ расчёта. В основу расчётов положено уравнение баланса наносов транзитной струи.

Первый способ расчётов позволяет оценить последствия разработки подводных каналов, осуществляемой способом землечерпания. На участке 
работ в этом случае изменяется гидравлическая ситуация, и возникает шлейф дополнительной мутности, который обусловлен не только нарушением режима скоростей и увеличением глубин, но воздействием механизмов на грунт, потерей грунта из ковша в процессе технологического цикла.

В расчётах по первому способу важное значение имеет определение

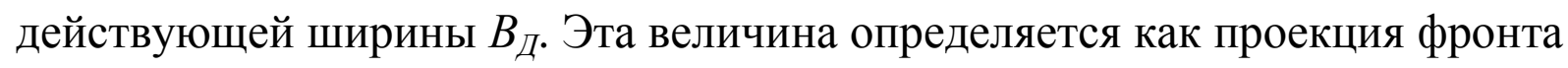
проводимых работ на направление перпендикулярное оси $X$, и соответствует ширине потока в начальном створе. Под фронтом работ понимается участок производства работ протяженностью $B_{\Phi}$ в плоскости зеркала водотока и глубиной $L_{\Phi}$, измеряемой по перпендикуляру к $B_{\Phi}$. Для вычисления $B_{д}$ предлагается использовать формулу (17):

$$
B_{\text {д }}=B_{\phi} \cdot \sin \beta+L_{\phi} \cdot \cos \beta,
$$

где: $B_{\phi}-$ фактическая ширина фронта работ;

$L_{\phi}$ - фактическая глубина разработки грунта;

$\beta$ - угол между линией фронта проводимых работ и направлением течения (изменяется от 0 до $90^{\circ}$ ).

Значение мутности взмыва находится по формуле (18):

$$
S_{\text {6зм. }}=\frac{0,15 \cdot N \cdot v^{2}}{h}
$$

где: $h$ - средняя глубина водотока;

$v$ - средняя скорость течения в водотоке;

$N$ - безразмерное характеристическое число, зависимое от коэффициента Шези $(C)$ и её производной $(M)$.

Мутность в начальном створе расчётного участка рассчитывается по формуле (19):

$$
S_{H}=\frac{P \cdot p_{0} \cdot m \cdot\left(0,01 \cdot \sum P_{i}\right)}{Q_{\text {д }}},
$$

где: $P$ - производительность одного ковша машины; 
$p_{0}-$ плотность смеси воды и грунта в ковше;

$m$ - понижающий коэффициент к производительности землеройных машин при разработке грунта из под воды;

$Q_{д}-$ действующий расход воды в пределах фронта работ;

$\Sigma P_{i}$ - суммарный процент содержания фракций транспортируемых во взвешенном состоянии.

При выполнении расчётов учитывается, что в большинстве случаев $p_{0}<p_{\text {грунта }}$.

\section{Особенности расчёта концентраций взвесей при работах по} отсыпке дамб

Для учёта особенностей распространения и седиментации дополнительной мутности при работах по отсыпке дамб, согласно Методике (1987), в формулы (17)-(19) вносятся следующие изменения. В формулу мутности взмыва (18) вводится дополнительный множитель $(1-\sin \gamma)$, учитывающий угол откоса $\gamma$, формирующегося при отсыпке грунта в голове дамбы:

$$
S_{\text {взи. }}=\frac{0,3 \cdot N \cdot v^{2}}{h \cdot(1-\sin \gamma)} \text {. }
$$

Поскольку поступление наносов в районе откоса дамбы происходит только за счёт естественного размыва под влиянием течения водотока, начальная мутность в этом случае будет равна мутности взмыва на естественном откосе с углом $\gamma$, то есть:

$$
S_{H}=S_{\text {взм }} \text {. }
$$

Под фронтом работ в данном случае понимается ширина зоны, расположенной в торцевой части дамбы, где производится отсыпка грунта. Принимается, что направление течения перпендикулярно оси дамбы, т. е. направлено параллельно её торцевой части. При этом ширина области взмучивания, обозначается также $B_{Д}$, и соответствует размерам конуса отсыпки грунта. Значение $B_{д}$ определяется по формуле (22): 


$$
B_{\text {д }}=\frac{h}{\operatorname{tg} \gamma},
$$

где: $\gamma$ - угол откоса насыпи дамбы.

\section{Модельный расчёт площади и ширины шлейфа дополнительной}

\section{мутности}

Для проведения дальнейших расчётов и определения интегральных параметров проводится расчёт необходимого набора площадей $P_{i}$ и поперечных размеров облака взвеси $B_{2 i}$. Согласно экспериментам угол расхождения потока взвеси составляет 11-14, обычно его принимают равным $13^{\circ}$.

Для расчёта площади занятой взвесью, и поперечных размеров облака взвеси, необходимо задать следующие параметры (рис. 4):

$b_{c p}-$ средняя ширина живого сечения русла;

- ширина облака взвеси в створе проведения работ;

- расстояние от левого берега до облака взвеси;

$\alpha-$ угол расхождения потока.

В расчётах ширина $B_{l}$ принимается равной фактической ширине фронта работ $\mathrm{B}_{\phi}$. В случае малых водотоков величину $B_{1}$ можно считать равной ширине реки.

Для проведения расчётов русло считается прямолинейным. В случае расстояния до створа 150 м и менее можно принять гипотезу о том, что интенсивность диффузионного перемешивания зависит линейно от интенсивности конвективного переноса и составляет приблизительно $23,1 \%$ (что соответствует тангенсу угла в $13^{\circ}$ ). При расстояниях до створа более 150 м преобладание конвективного переноса над диффузионными процессами усиливается. 


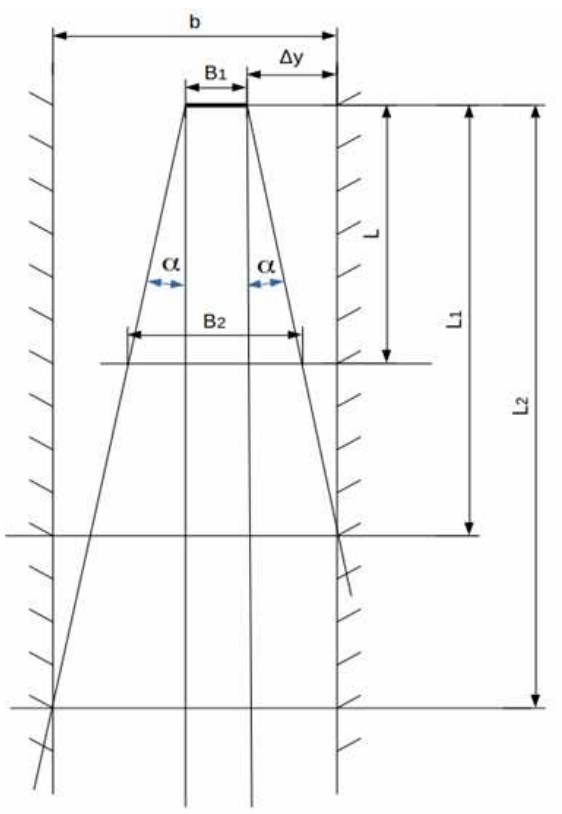

Рисунок 4 - Схема расположения основных параметнов распространения взвеси в водотоке

Площадь облака $P(L)$ рассчитывается по формуле (23), при этом применяемые величины соответствуют обозначениям рисунка 4:

$\mathbf{\square}\left(P(L)=B_{\downarrow} 1 L+\mathbb{U}\left(\left(L^{\dagger} 2 \operatorname{tg} \alpha\right) / 2,0 \leq L<L_{\downarrow} 1 @\left(\Delta y L_{\downarrow} 1\right) / 2+\Delta y\left(L-L_{\downarrow} 1\right), L_{\downarrow} 1 \leq L\right)\right\}+@ @$

$$
\begin{gathered}
L_{1}=\frac{\Delta y}{\operatorname{tg} \alpha}, \\
L_{2}=\frac{b_{c p}-B_{1}-\Delta y}{\operatorname{tg} \alpha} .
\end{gathered}
$$

Ширина облака $B_{2}(L)$ находится по формуле (24):

$$
B_{2}(L)=B_{1}+\left\{\begin{array}{cl}
L \cdot \operatorname{tg} \alpha, & 0 \leq L \leq L_{1} \\
\Delta y, & L_{1} \leq L
\end{array}\right\}+\left\{\begin{array}{cc}
L \cdot \operatorname{tg} \alpha, \quad 0 \leq L<L_{1} \\
b_{c p}-B_{1}-\Delta y, & L_{2} \leq L
\end{array}\right\} .
$$

Границами расчётных зон распространения мутности принимаются створы, до которых происходит полное оседание на дно выделенных фракций грунта.

Значения толщины слоя наилка и удельной плотности заиления рассчитываются как средние в зоне, поэтому эти значения относятся к створу реки в середине зоны. 
В предположении, что оседание частиц происходит равномерно по длине водотока, график зависимости изменения величин концентраций дополнительной мутности, толщины наилка и плотности заиления с расстоянием от створа работ позволяет получить эти значения в любом створе в пределах участка воздействия.

\section{Модельный расчёт интегральных показателей}

Определение интегральных показателей (объём воды, протёкшей через области шлейфа с заданной концентрацией взвеси; средний слой наилка; удельная плотность заиления дна в расчётной зоне) проводится по Методу ГГИ [11], для этого рассчитываются границы зон полного осаждения фракций заданного размера $\left(L_{i}\right)$ :

$$
L_{i}=\frac{h \cdot v}{u_{i}}
$$

где: $h$ - средняя глубина водотока;

$v$ - средняя скорость течения в водотоке;

$u_{i}$ - средняя гидравлическая крупность взвешенных загрязняющих частиц (расчётная крупность).

Далее каждой зоны определяется масса грунта каждой фракции $G_{i j}^{\prime}$ осевшая в $i$-ой зоне:

$$
G_{i j}^{\prime}=G_{i} \cdot \frac{L_{i}}{L}-\sum G_{i(j-n)}^{\prime},
$$

где: $G_{i}-$ масса грунта, поступившая в поток $i$-ой фракции;

$L_{i}$ - длина расчётной зоны;

$L$ - расстояние от створа работ до створа полного оседания расчётной фракции;

$\sum G_{i(j-n)}^{\prime}$ - масса грунта данной фракции, осевшая в предыдущих расчётных зонах выше по течению.

Суммированием $G_{i j}^{\prime}$ получаем массу грунта, осевшую в каждой зоне. 
В результате формируется интегральная сумма массы осевшего грунта в русле от створа проведения работ до каждого расчётного створа с учётом массы транзитного грунта.

С учётом гранулометрического состава отложившихся фракций с поправкой на разрыхление (так как отложения являются свежими) определяется объём отложений $(W)$, площадь дна водотока $(F)$, средний слой наилка $(\delta)$ и удельная плотность заиления дна (ל) в каждой расчётной зоне.

Работы могут производиться последовательно или одновременно на нескольких участках водотока. Если работы производятся одновременно в разных створах речного русла, облака взвеси могут пересекаться; в этих областях плотности будут суммарными. Отложения на дне, образующиеся от производства работ на различных участках также будут суммироваться. Для упрощения расчётов будем считать, что протяженность участка, на котором проводятся работы, незначительна по сравнению с предполагаемой длиной облака мутности, и, можно полагать, что взвесь поступает в воду в одном створе. Для более сложных случаев общий результат можно получить, как суперпозицию результатов расчёта отдельных простых конфигураций. При этом необходимо сохранять промежуточные результаты для получения в итоге решения общей задачи.

Исходные данные для проведения моделирования вносятся в соответствующие графы программы (рис. 5). 


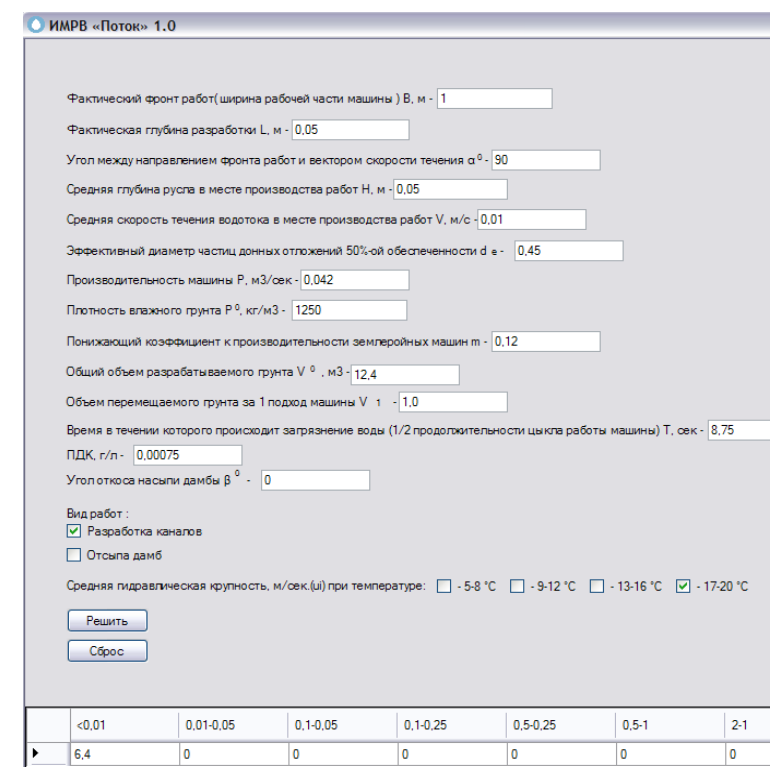

Рисунок 5 - Пример формирования исходных данных для моделирования распространения облака взвеси, образующейся в ходе работ в русле водотока

Получаемые в результате моделирования промежуточные результаты имеют следующий вид (рис. 6).

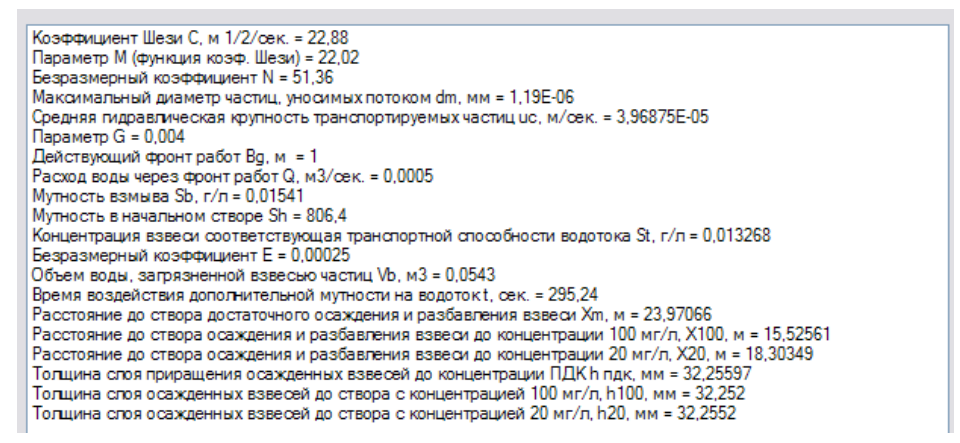

Рисунок 6 - Пример промежуточных результатов моделирования распространения облака взвеси, образующейся в ходе работ в русле водотока

Изменение концентрации взвеси в воде в зависимости от расстояния от места производства работ отображается также в графическом виде (рис. 7). 


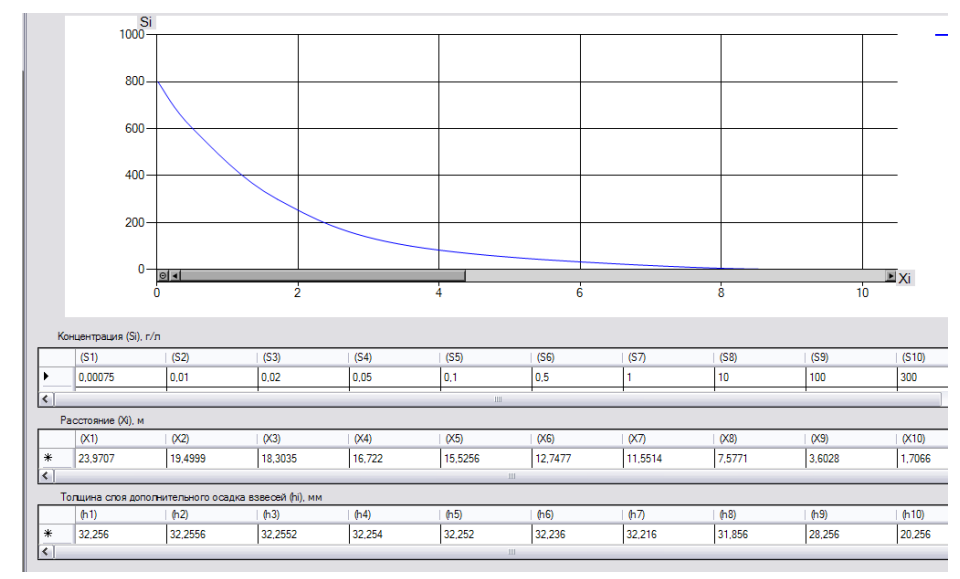

Рисунок 7 - Пример графического изображения данных об изменении концентрации взвеси в воде в зависимости от расстояния от фронта работ

Полученные в ходе имитационного моделирования итоговые данные вносятся в таблицу (табл. 2).

Таблица 2 - Пример формирования итоговой таблицы рассчитанных параметров распространения и интегральных показателей распространения шлейфа мутности

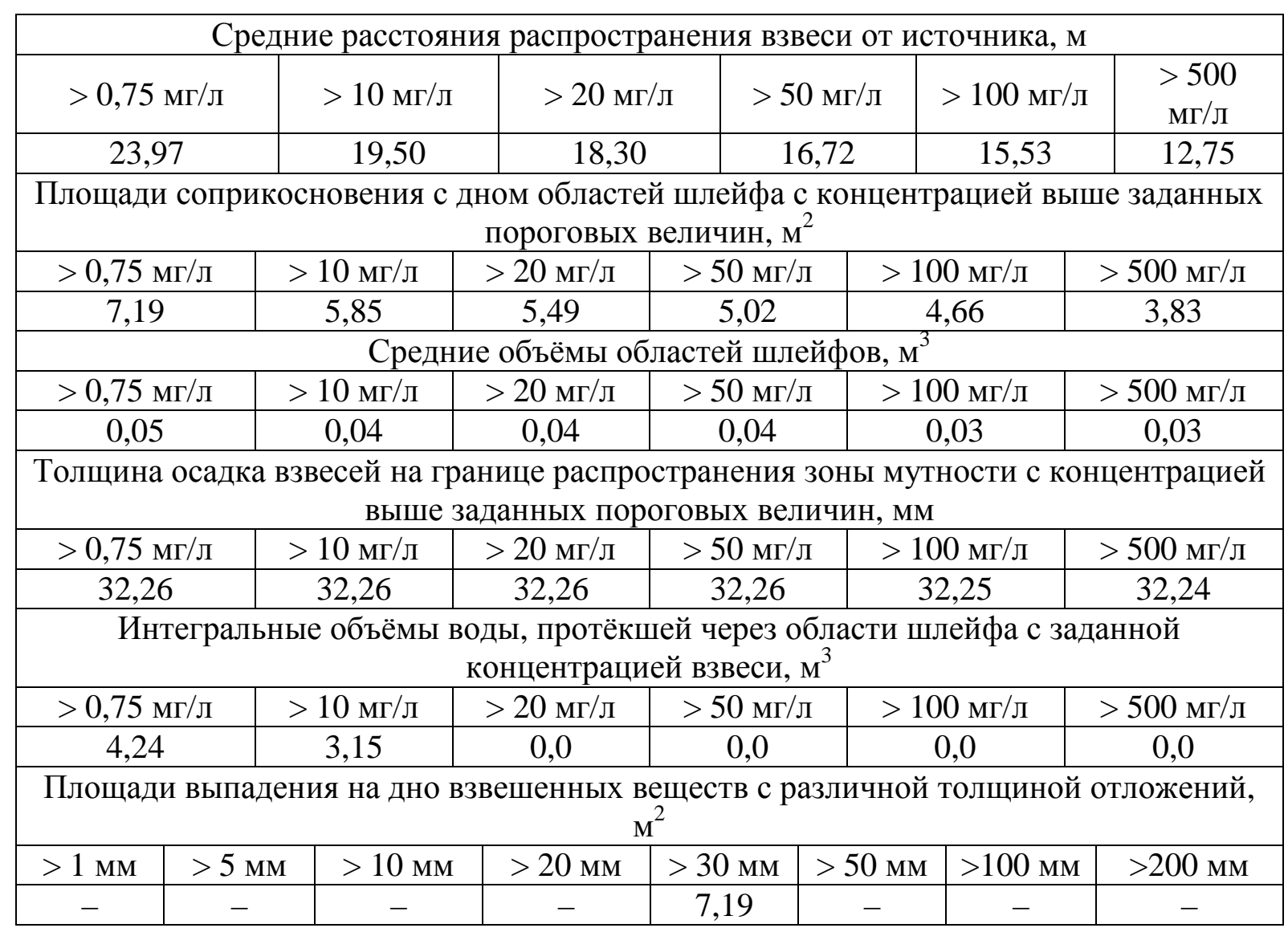




\section{Литература}

1. ВСН 486-86. Обеспечение охраны водной среды при производстве работ гидромеханизированным способом. - М., 1986. - 22 с.

2. ГН 2.1.5.1315-03. Предельно допустимые концентрации (ПДК) химических веществ в воде водных объектов хозяйственно-питьевого и культурно-бытового водопользования. - М., 2003. - 173 с.

3. ГОСТ 19179-73. Гидрология суши. Термины и определения. - М.: Изд-во стандартов, $1975 .-34$ с.

4. ГОСТ 17.1.1.02-77. Охрана природы. Гидросфера. Классификация водных объектов. - М.: Изд-во стандартов, 1977. - 44 с.

5. ГОСТ 17.1.3.07-82. Охрана природы. Гидросфера. Правила контроля качества воды водоемов и водотоков. - М.: Изд-во стандартов, 1982. - 81 с.

6. ГОСТ 27065-86. Качество вод. Термины и определения. - М.: ИПК Изд-во стандартов, 1987. - 8 с.

7. ГОСТ 17.1.3.13-86. Охрана природы. Гидросфера. Общие требования к охране поверхностных вод от загрязнения. - М.: Изд-во стандартов, 1986. - 138 с.

8. ГОСТ 8267-93. Щебень и гравий из плотных горных пород для строительных работ. Технические условия. - М.: Стандартинформ, 2008. - 13 с.

9. ГОСТ 12536-2014. Грунты. Методы лабораторного определения гранулометрического (зернового) и микроагрегатного состава. - М.: Стандартинформ, 1982. - 19 c.

10. Добронравов, С. С. Строительные машины и оборудование: Справочник / С. С. Добронравов, М. С. Добронравов. - М.: Высш. шк., 2006. - 445 с.

11. Добыча нерудных строительных материалов в водных объектах. Учёт руслового процесса и рекомендации по проектированию и эксплуатации русловых карьеров: Стандарт организации (СТО 52.08.31-2012). - СПб.: Глобус, 2012. - 140 с.

12. Методика исчисления размера вреда, причинённого водным биологическим ресурсам / Утверждена приказом Федерального агентства по рыболовству №1166 от 25.11.2011 г. - М., 2011. - 97 с.

13. Методические основы оценки и регламентирования антропогенного влияния на качество поверхностных вод / под ред. А. В. Караушева. - Л.: Гидрометеоиздат, 1987. $-285 \mathrm{c}$.

14. Об утверждении нормативов качества воды водных объектов рыбохозяйственного значения, в том числе нормативов предельно допустимых концентраций вредных веществ в водах водных объектов рыбохозяйственного значения / Федеральное агентство по рыболовству. Приказ от 10.01.2010 г. №20.

15. РП.1.204-1-84. Кабельные переходы связи через водные преграды с учётом требований охраны окружающей среды. Методическое руководство по проектированию. - М., 1984. - 103 с.

\section{References:}

1. VSN 486-86. Obespechenie ohrany vodnoj sredy pri proizvodstve rabot gidromehanizirovannym sposobom. - M., 1986. $-22 \mathrm{~s}$.

2. GN 2.1.5.1315-03. Predel'no dopustimye koncentracii (PDK) himicheskih veshhestv $\mathrm{v}$ vode vodnyh ob\#ektov hozjajstvenno-pit'evogo i kul'turno-bytovogo vodopol'zovanija. M., 2003. - $173 \mathrm{~s}$.

3. GOST 19179-73. Gidrologija sushi. Terminy i opredelenija. - M.: Izd-vo standartov, 1975. $-34 \mathrm{~s}$. 
4. GOST 17.1.1.02-77. Ohrana prirody. Gidrosfera. Klassifikacija vodnyh ob\#ektov. M.: Izd-vo standartov, 1977. - $44 \mathrm{~s}$.

5. GOST 17.1.3.07-82. Ohrana prirody. Gidrosfera. Pravila kontrolja kachestva vody vodoemov i vodotokov. - M.: Izd-vo standartov, 1982. - $81 \mathrm{~s}$.

6. GOST 27065-86. Kachestvo vod. Terminy i opredelenija. - M.: IPK Izd-vo standartov, 1987. $-8 \mathrm{~s}$.

7. GOST 17.1.3.13-86. Ohrana prirody. Gidrosfera. Obshhie trebovanija k ohrane poverhnostnyh vod ot zagrjaznenija. - M.: Izd-vo standartov, 1986. - $138 \mathrm{~s}$.

8. GOST 8267-93. Shheben' i gravij iz plotnyh gornyh porod dlja stroitel'nyh rabot. Tehnicheskie uslovija. - M.: Standartinform, 2008. - 13 s.

9. GOST 12536-2014. Grunty. Metody laboratornogo opredelenija granulometricheskogo (zernovogo) i mikroagregatnogo sostava. - M.: Standartinform, 1982. $-19 \mathrm{~s}$.

10. Dobronravov, S. S. Stroitel'nye mashiny i oborudovanie: Spravochnik / S. S. Dobronravov, M. S. Dobronravov. - M.: Vyssh. shk., 2006. - 445 s.

11. Dobycha nerudnyh stroitel'nyh materialov v vodnyh ob\#ektah. Uchjot ruslovogo processa i rekomendacii po proektirovaniju i jekspluatacii ruslovyh kar'erov: Standart organizacii (STO 52.08.31-2012). - SPb.: Globus, 2012. - $140 \mathrm{~s}$.

12. Metodika ischislenija razmera vreda, prichinjonnogo vodnym biologicheskim resursam / Utverzhdena prikazom Federal'nogo agentstva po rybolovstvu №1166 ot 25.11.2011 g. - M., 2011. - 97 s.

13. Metodicheskie osnovy ocenki i reglamentirovanija antropogennogo vlijanija na kachestvo poverhnostnyh vod / pod red. A. V. Karausheva. - L.: Gidrometeoizdat, 1987. $285 \mathrm{~s}$.

14. Ob utverzhdenii normativov kachestva vody vodnyh ob\#ektov rybohozjajstvennogo znachenija, v tom chisle normativov predel'no dopustimyh koncentracij vrednyh veshhestv v vodah vodnyh ob\#ektov rybohozjajstvennogo znachenija / Federal'noe agentstvo po rybolovstvu. Prikaz ot 10.01.2010 g. №20.

15. RP.1.204-1-84. Kabel'nye perehody svjazi cherez vodnye pregrady s uchjotom trebovanij ohrany okruzhajushhej sredy. Metodicheskoe rukovodstvo po proektirovaniju. M., 1984. - $103 \mathrm{~s}$. 